Original research article

\title{
Rosuvastatin, Perindopril and Ezetimibe loaded instant release buccal films: Development and in vitro characterization
}

\author{
Sobia Anwar ${ }^{1}$, Muhammad Zaman ${ }^{1,2}$, Maria Abdul Ghafoor Raja ${ }^{3}$, Asif Mahmood ${ }^{1}$, \\ Muhammad Wahab Amjad ${ }^{3 *}$ \\ ${ }^{1}$ The University of Lahore, Faculty of Pharmacy, Department of Pharmaceutics, Lahore, Pakistan \\ ${ }^{2}$ University of Central Punjab, Faculty of Pharmacy, Department of Pharmaceutics, Lahore, Pakistan \\ ${ }^{3}$ Northern Border University, Faculty of Pharmacy, Department of Pharmaceutics, Rafha, Kingdom of Saudi Arabia
}

\begin{abstract}
Background: Rosuvastatin Calcium and Ezetimibe are used to control cholesterol level while Perindopril Erbumine is used to treat hypertension. Hepatic metabolism reduces the therapeutic effect of these drugs.

Objective: Instant release buccal films (IRBFs) could possibly be a solution to this issue. The objective of the study was to formulate IRBFs of Rosuvastatin Calcium, Perindopril Erbumine and Ezetimibe using solvent casting technique.

Methods: Polymers used to prepare IRBFs included hydroxypropyl methylcellulose (HPMC E5), PEG 400 (as plasticizer) and Tween 80 (as surfactant). Solvent casting technique was used to fabricate the films, followed by their in-vitro analysis including high performance liquid chromatography (HPLC), X-ray diffraction (XRD), fourier transform infrared evaluation (FTIR), In-vitro dissolution, In-vitro disintegration, stability tests, scanning electron microscopy (SEM), folding fortitude, thickness evaluation, surface $\mathrm{pH}$, tensile strength, weight variation and percentage moisture content.

Results: Optical microscopy as well as SEM analysis displayed that the surfaces of IRBFs were smooth with uniform mixing of ingredients. IRBFs disintegrated within 15 seconds while on dissolution they exhibited instant drug release i.e. 100\% release in 2 minutes. Conclusions: The results show promising potential of IRBFs in drug delivery.
\end{abstract}

Keywords: Buccal films; Ezetimibe; Instant release; Perindopril; Rosuvastatin

\section{Highlights:}

- Smooth uniformly mixed IRBFs were formulated.

- IRBFs disintegrated quickly and released $100 \%$ drug within 2 minutes.

- IRBFs show promising potential in drug delivery.

\section{Introduction}

Hypercholesterolemia is defined as exceptionally elevated blood cholesterol levels (Durrington, 2003). It is also known as hyperlipidemia and hyperlipoproteinemia.

Hypertension (HTN) is described as constantly elevated arterial pressure (Tabrizi et al., 2016). Arterial hypertension is frequently observed in combination with hypercholesterolemia. Drugs which are used against hypercholesterolemia include Rosuvastatin Calcium and Ezetimibe while hypertension can be managed by using Perindopril Erbumine. Rosuvastatin Calcium is the 7 th drug that is prescribed along with diet, exercise and weight reduction to mitigate high cholesterol level (Quirk et al., 2003). Ezetimibe also belongs to cholesterol reducing medication class of drugs. It is used solely or in combination with statins i.e. HMG-CoA reductase inhibitor. Perindopril Erbumine is included in long acting ACE inhibitors class, which is used to mitigate elevated blood pressure, medicate coronary artery ailments and cardiac failures. All abovementioned drugs face challenges including poor bioavailability. Another limitation about these drugs is that they are not available in combination in a single tablet/capsule thereby reducing patient compliance.

Buccal route is considered to be one the most exclusive and highly acceptable ways of drug intake (Shojaei et al., 2001). There are three different categories for the delivery of drugs within the buccal cavity including buccal, local and sublingual (Patel et al., 2012).

An alternative to tablets and capsules are immediate released buccal films, which promote patient compliance and dissolve rapidly in the buccal cavity (Hanif et al., 2015). These

\footnotetext{
* Corresponding author: Muhammad Wahab Amjad, Northern Border University, Faculty of Pharmacy, Department of Pharmaceutics, Rafha 91911, P.O. Box 840, Kingdom of Saudi Arabia; e-mail: mwbamjad@yahoo.com http://doi.org/10.32725/jab.2020.015 
buccal films when placed on the tongue dissolve and disintegrate rapidly without the need of water hence improving patient compliance (Kumar et al., 2013).

Characteristics of immediate release buccal films totally rely on the polymers utilized to fabricate films, which constitute $20-75 \% \mathrm{w} / \mathrm{w}$ of entire weight. The use and selection of polymers should be evaluated in terms of palatability, safety and effectiveness for patients. Polymers are used in film formulations to release the drug in appropriate and controlled way and provide elasticity. To tolerate the environmental pressure, these films use special polymers to regain the appropriate elasticity, flexibility, mechanical and tensile strength.

Polymers, which are used in the fabrication of buccal films, are either natural (i.e. polysaccharides, starch, acacia gum, tragacanth gum, gelatin etc.) or synthetic (i.e. hydroxypropyl methylcellulose, polyvinyl alcohol, polyacrylic acids, and carboxyvinyl polymers). The polymer used in this study is Hydroxypropyl Methylcellulose (HPMC E5) while Polyethylene glycol 400 (PEG 400) acts as a plasticizer. Tween 80, a polyethylene sorbitol ester, is used as a nonionic surfactant (Chou et al., 2005). To enhance the palatability mannitol and peppermint oil were used as sweetening and flavoring agents.

In this study HPMC E5, PEG 400 and Tween 80 were used to prepare instant release buccal films. The drugs were loaded individually as well as in combination onto the buccal films i.e. Rosuvastatin Calcium in combination with Perindopril and Rosuvastatin in combination with Ezetimibe. The films were extensively characterized using various techniques.

\section{Materials and methods}

\section{Materials}

Rosuvastatin Calcium, Perindopril Erbumine and Ezitimibe were received as a generous gift from CCL Pharmaceuticals, Lahore, Pakistan. Hydroxypropyl methylcellulose E5 (HPMC-E5), Polyethylene glycol (PEG-400), Tween 80, Amaranth color, Sodium hydroxide $(\mathrm{NaOH})$, Hydrochloric acid $(\mathrm{HCl})$, Potassium dihydrogen phosphate $\left(\mathrm{KH}_{2} \mathrm{PO}_{4}\right)$, Orthophosphoric acid, Diethyl ether, Methanol, Acetonitrile and Ethanol were purchased from Merck Darmstadt, Germany. Peppermint oil was purchased from Pulcra Chemicals Shanghai, China.

\section{Methods}

Formulation design

To design and optimize the formulations of instant release buccal films, Design-Expert software version 7.0 was used, employing Central composite rotatable design (CCRD) approach. Various formulations were selected to synthesize buccal film formulations. Concentrations of HPMC E5 and PEG 400 were variable while those of Tween $80(0.3 \mathrm{ml})$, peppermint oil (1-2 drops), amaranth color (1-2 drops) and solutions of Rosuvastatin Calcium (5 mg), Perindopril Erbumine ( $5 \mathrm{mg}$ ) and Ezetimibe $(10 \mathrm{mg})$ were kept constant in all the formulations.

Preparation of instant release buccal films (IRBFs) by solvent casting technique

IRBFs of Rosuvastatin Calcium, Perindopril Erbumine and Ezetimibe were formulated according to the dosage constitutions as described in Table 1 . The formulations (1-10) had various weight ratios of HPMC-E5 (film forming polymer) to PEG 400 (plasticizer). Based on literature review, we tried to discover the optimum weight ratio, which could yield the buccal films with optimum physicochemical and mechanical properties.
Initial characterization studies revealed formulations ' 5 'and ' 6 ' to possess better properties than others and were taken ahead for further detailed investigations.

Table 1. Formulation design for buccal films

\begin{tabular}{ccc}
\hline Formulation codes & HPMC-E5 $(\mathrm{mg})$ & PEG $400(\mathrm{mg})$ \\
\hline 1 & 150 & 21.89 \\
2 & 150 & 32.5 \\
3 & 125 & 40 \\
4 & 150 & 43.11 \\
5 & 185 & 32.50 \\
6 & 150 & 21.89 \\
7 & 175 & 25 \\
8 & 114.64 & 32.50 \\
9 & 175 & 40 \\
10 & 125 & 25 \\
\hline
\end{tabular}

Initially, required amount of PEG 400 solution was taken in separate beakers and stirred on a hot plate magnetic stirrer. $0.2 \mathrm{ml}$ Tween 80 from the stock solution was added and stirred for about 5 min. Afterwards, 1-2 drops of peppermint oil \& amaranth color solution were added and stirred for 15 min. The required amounts of Rosuvastatin Calcium, Perindopril Erbumine and Ezitimibe were added individually in separate films and stirred for at least $15 \mathrm{~min}$. For the preparation of drug combinations, respective drugs were added one after another, followed by a 15 min stirring. After mixing of all ingredients, the required quantity of HPMC-E5 solution (polymer) was added followed by stirring for $45-50 \mathrm{~min}$. The mixtures were poured in glass Petri dishes and an inverted funnel was placed over each Petri dish in order to facilitate uniform evaporation. The petri dishes were then placed in hot air oven at $400{ }^{\circ} \mathrm{C}$ for 24 hours. After drying, each film was peeled off from the petri dishes using a sharp cutter. The films were wrapped in aluminum foil to protect them from contamination and were stored in a desiccator at room temperature.

\section{Physiochemical evaluation of buccal films}

\section{Surface morphology}

Visual inspection

This evaluation consisted of characteristics such as transparency, color, visual uniformity, shining, proper mixing of ingredients and surface touch (Kumria et al., 2016). These formulations were categorized as poor, average, good, better, best and excellent as per order according to the fulfillment of their desired characteristics.

\section{Optical microscopy}

Optical microscopy of each buccal film was done to analyze them at micro levels (Preis et al., 2013). Glass slide containing small strip of each film separately was observed under microscope at $10 \times$ and $40 \times$ magnifications and images were captured.

Scanning electron microscopy (SEM)

The surface morphology of the samples was analyzed and studied thoroughly by using SEM.

\section{$X$-ray diffraction $(X R D)$}

XRD studies were done on all three drugs used and the best formulations were prepared (Nair et al., 2013). 
Thermal gravimetric analysis (TGA)

TGA was performed of all drugs using thermal gravimetric analyzer (Kianfar et al., 2012).

\section{Evaluation of mechanical properties}

Folding endurance

The folding resilience of a strip to rupture is called folding endurance. The strip of a film was held in index finger and thumbs of the two hands and was folded several times at the same point until it cracked or broke. The number of folds of the strip at the same point was counted (Prabhu et al., 2011).

Tack test

The substance which is not completely dry and is sticky in touch is called tacky. It is difficult to pack multi-dosed films in one container because of tacky characteristic. Therefore, two films can be kept separate from one another by placing a paper between them during packaging. According to the stickiness of the films to the paper, they were classified as very tacky, tacky, slightly tacky and tack-free (Chaudhary et al., 2013).

\section{Thickness}

Screw gauge was used to measure the thickness of the films. The uniform thickness of the films is an essential factor for uniform dose distribution (Irfan et al., 2016).

\section{Tensile strength}

Tensile strength of instant released buccal films was calculated by using Brookfield CT3 texture analyzer. The maximum force needed to tear the films was recorded and it was the end point of the resistance to tear the films (Chatap et al., 2013). Tensile strength of the films was calculated by using the following formula

$$
\text { Tensile strength }=\frac{\text { Rupture force }}{(\text { thickness } \times \text { width })}
$$

\section{pH determination}

Sometimes local buccal irritation occurs due to basic or acidic $\mathrm{pH}$ of buccal film formulations. The $\mathrm{pH}$ of the buccal cavity ranges from 5.5 to 7.4 . Firstly, we cut a strip of size $2 \times 2 \mathrm{~cm}^{2}$ from each film and placed it in a beaker containing $5 \mathrm{ml}$ distilled water followed by allowing it to dissolve (Jadhav et al., 2012). After dissolution, $\mathrm{pH}$ of the strip solution was measured by using $\mathrm{pH}$ meter.

\section{In-vitro disintegration and total dissolution time}

Each film was cut into 4 pieces and a quarter was placed in beaker containing $5 \mathrm{ml}$ distilled water. A stop watch was used to record the time as the film started to dissolve. The time which a film takes to start dissolving is called disintegration time while the time taken to completely dissolve is called dissolution time (El-Setouhy and El-Malak, 2010). Both disintegration and dissolution times were recorded.

\section{Weight uniformity}

Weight compatibility is an essential parameter in determining the dose of each film formulation (Morales and McConville, 2011). By using electronic weighing balance, three films of each formulation were weighed individually followed by calculation of mean and standard deviation.

\section{Percentage moisture loss}

Three strips of each film were cut and weighed followed by placement in a hot air oven previously set to a temperature of $50{ }^{\circ} \mathrm{C}$. After complete drying, the films were weighed again individually. Percentage of moisture loss was calculated using the following formula

$$
\% \text { Moisture content }=\left(W o-\frac{W d}{W o}\right) \times 100
$$

where Wo is the initial (before drying) weight of the film and $\mathrm{Wd}$ is the weight of the dried film (Bajdik et al., 2009).

\section{Percentage drug contents}

Percentage drug content test was performed to evaluate the drug content in each strip by following standard assay method. Individual strip was dissolved in $250 \mathrm{ml}$ medium (using phosphate buffer at $\mathrm{pH}$ 6.8). Absorbance was calculated at wavelengths of $243 \mathrm{~nm}, 215 \mathrm{~nm}$ and $247 \mathrm{~nm}$ for Rosuvastatin Calcium, Perindopril Erbumine and Ezetimibe IRBFs, respectively. The results were compared with the standard dilutions of individual drugs followed by the calculation of percentage drug content.

\section{In-vitro drug release studies}

For in-vitro drug release study USP paddle type II apparatus was used. Owing to the stability of drugs in water, $250 \mathrm{ml}$ phosphate buffer at $\mathrm{pH} 6.8$ was used as the dissolution medium. A quarter of the film strip was taken and fixed on the glass slide using paper clips followed by its placement inside the vessel set at $37 \pm 0.5^{\circ} \mathrm{C}$ and time was recorded. The samples were withdrawn at predefined time intervals i.e. $2,4,6,8,10,15$, 20, 30 and 60 min and the same volume of phosphate buffer was added in the vessel to make up the volume. This procedure was adopted for the determination and evaluation of all three drugs. T80 Double Beam UV spectrophotometer was used for the calculation of absorbance of the drawn samples and evaluation of percentage drug release.

High Performance Liquid Chromatographic (HPLC) analysis HPLC analysis has been performed by using HPLC (CTO20A/20AC SHAMIDZU Japan), equipped with column (Kromasil ${ }^{\circledR}$ C18 HPLC Column, $250 \mathrm{~mm} \times 4.6 \mathrm{~mm}, 5 \mu \mathrm{m}$ particle size) and CTO-20A Column Oven (SHAMIDZU Japan), to validate the drug contents and drug release of the films, co-loaded with Rosuvastatin-Perindopril and Rosuvastatin-Ezitimibe evaluated by using UV-Visible spectrophotometer. For this purpose, it has been tried to find out a single wavelength to detect the combination of the drugs, simultaneously. Linearity curves have been drawn by using area under the curve (AUC) obtained by running the sample at HPLC.

Different organic solvents and their combination with buffers of different $\mathrm{pH}$ were tried to find out the best suitable solvent mixture to prepare the stock solution of the analytes. Methanolic phosphate buffer was found suitable due to better solubility of analytes in it. Standard solution of Rosuvastation Calcium and Perindopril, and Rosuvastatin Calcium and Ezitimibe were prepared separately in volumetric flasks having $50 \mathrm{ml}$ volumetric capacity. Standard solution of both combinations, having $50 \mu \mathrm{g} / \mathrm{ml}$ of each drug was prepared, followed by the preparation of serial dilutions of 5 to $30 \mu \mathrm{g} / \mathrm{ml}$ for each drug by diluting the standard solution with the mobile phase, consisted of Methanol-phosphate buffer-acetonitrile (70: $25: 5, \mathrm{v} / \mathrm{v}$, adjusted to $\mathrm{pH} 3.5$ using orthophosphoric acid). Feasibility of different solvent systems such as methanol-water, acetonitrile-water and acetonitrilephosphate buffer in different compositions, pumped at different flow rates (in the range of $0.5-1.5 \mathrm{ml} / \mathrm{min}$ ) having variable $\mathrm{pH}$ range (2.0-7.0) and at different column oven temperatures (in the range of $25-35^{\circ} \mathrm{C}$ ) were evaluated to find out the com- 
patible chromatographic conditions. Linearity curves have been drawn by running the dilutions of drugs in HPLC, which were further utilized to determine the drug contents and cumulative amount of drug released.

\section{Kinetic modeling of dissolution data}

Dissolution data of Rosuvastatin Calcium, Perindopril and Ezetimibe formulations were fitted in zero order, 1st order, Higuchi and Korsmeyer-Peppas models. These models were applied using DD Solver software.

Zero order kinetic model can be represented by the equation as:

$$
Q t=Q_{\mathrm{o}}+K_{\mathrm{o}} t
$$

First order kinetic model can be expressed by the equation as:

$$
\log C=\log C_{\mathrm{o}}-K t / 2.303
$$

Higuchi model can be described by the equation as:

$$
f t=Q=A \sqrt{D(2 C-C s) C s t}
$$

Korsmeyer-Peppas kinetic model used to find out the drug release mechanism can be equated as:

$$
M t / M \infty=K t^{n}
$$

\section{Results and discussions}

\section{Characterization of formulations \\ Visual inspection}

From the results of visual inspection, it was evaluated that at low concentration of PEG 400, formulations showed shiny surface whereas as its concentration increased the formulations lost their shine. Furthermore, at high concentrations of HPMC E5 the formulations showed better transparency, satisfactory uniformity and smooth surface and vice versa. Strips of all formulations were found to be smooth except those which contained decreased polymer concentrations and high plasticizer concentration.

\section{Light microscope}

Images of IRBFs of Rosuvastatin Calcium (R), Perindopril Erbumine (P), Ezetimibe (E), combinations of Rosuvastatin Calcium and Perindopril Erbumine (PR) \& Rosuvastatin Calcium and Ezetimibe (ER) were taken by using a light microscope model 4083B3 at a resolution of 10× (Fig. 1).

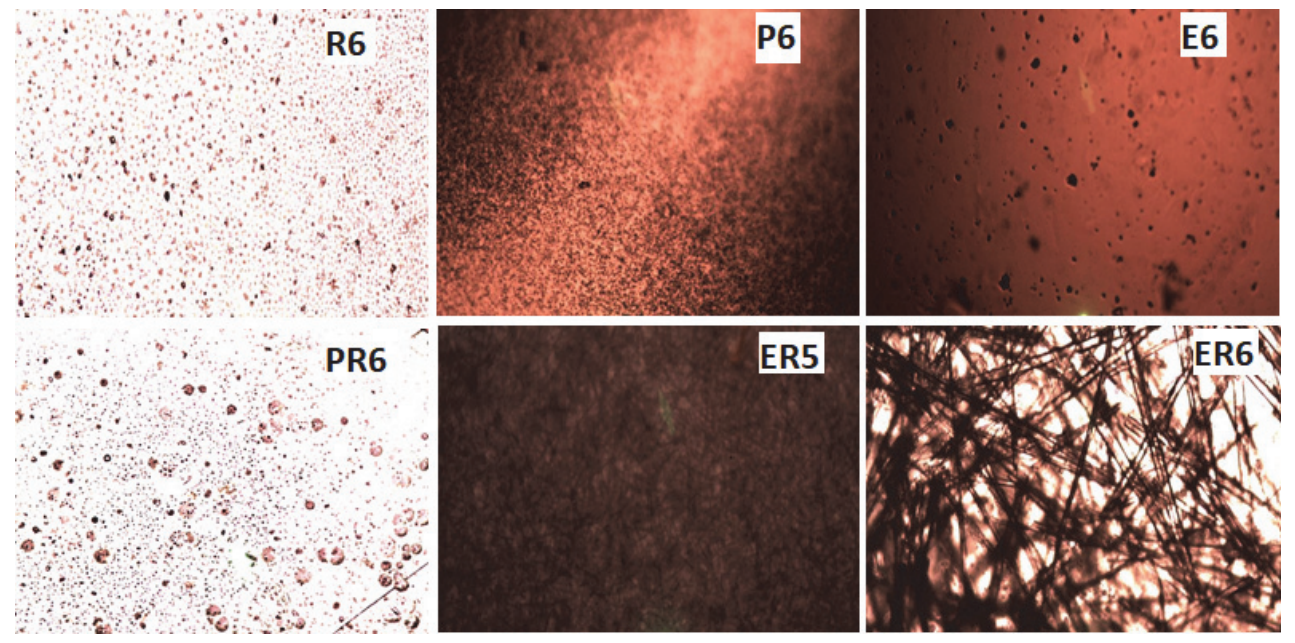

Fig. 1. Images of IRBFs of drugs and drug combinations

\section{Scanning Electron Microscope (SEM)}

The SEM figures exhibited that the formulations having least concentration of polymers had less clarity and vice versa (Fig. 2). However, at all plasticizer concentrations, strips having highest concentration of polymers had the maximum amount of drug loaded onto them. Depending on the concentrations of polymer and plasticizer, the surface of the IRBFs was found to be either clear or rough, and displayed whichever uniform or uneven distribution of the ingredients.

\section{$X$-Ray diffraction $(X R D)$ analysis}

X-ray diffraction pattern of Rosuvastatin Calcium exhibited sharp diffraction peaks at $2 \theta$ values of $34.3^{\circ}, 22.45^{\circ}$ and $16.04^{\circ}$ as shown in (Fig. 3). X-ray diffraction pattern of Perindopril Erbumine exhibited sharp diffraction peaks at $2 \theta$ values of $16.5^{\circ}, 15.3^{\circ}$ and $8.95^{\circ}$. X-ray diffraction pattern of Ezetimibe exhibited sharp diffraction peaks at $2 \theta$ values of $25.35^{\circ}, 22.4^{\circ}$ and $19.4^{\circ}$. While IRBFs of PR and ER formulations presented absence of characteristic peaks at $2 \theta$ which indicated that drugs had converted from crystalline form to amorphous ones. Their solubility was found to be increased because amorphous forms are better soluble than the crystalline forms (Tummala et al., 2015).

Thermal gravimetric analysis (TGA)

Thermal gravimetric analysis of pure drugs (Rosuvastatin Calcium, Perindopril Erbumine and Ezetimibe) and their IRBFs were performed to check their thermal stability (Fig. 4). TGA curve of Rosuvastatin Calcium narrates that the depletion in weight occurred as a result of thermal decomposition. The loss 


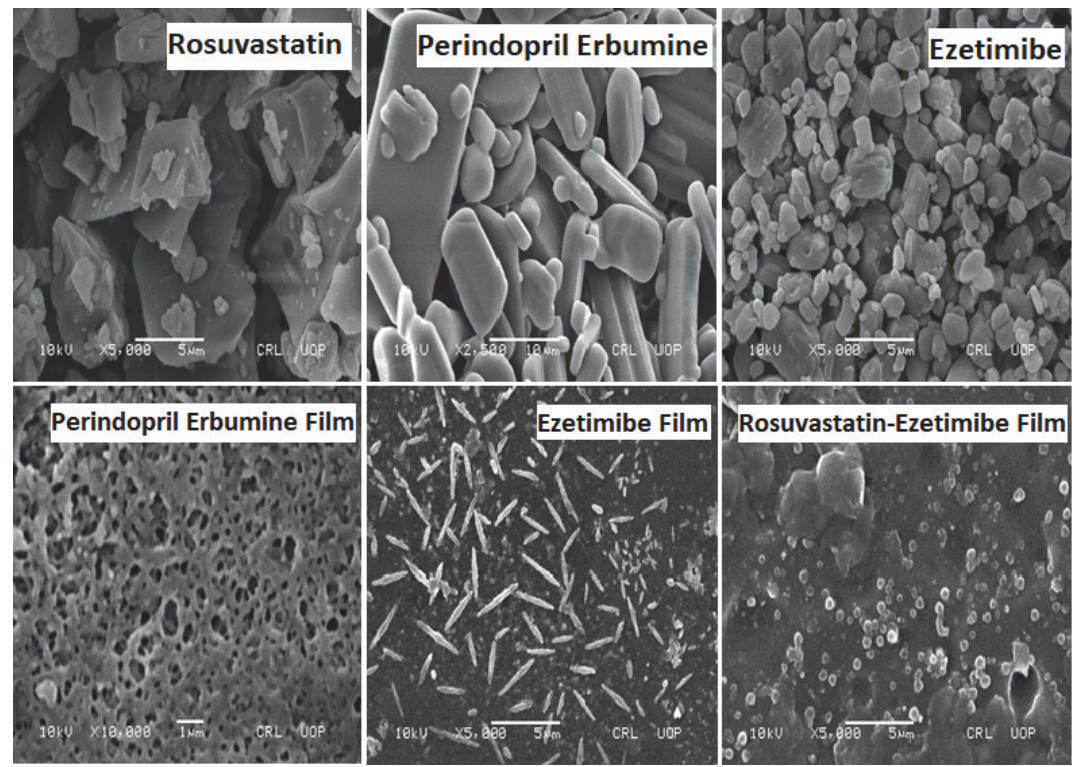

Fig. 2. $S E M$ images of individual drugs $R, P$ and $E$, IRBFs of $P$ and $E$ and IRBFs of $R E$ drug combination

of mass obtained is clearly evident from figures. TGA curve of pure drug Rosuvastatin Calcium exhibited $31.69 \%$ mass loss at $372.94{ }^{\circ} \mathrm{C}$ after 35.25 min. TGA curve of Perindopril Erbumine exhibited a loss of $46.2 \%$ mass at $260.52{ }^{\circ} \mathrm{C}$ in $24.68 \mathrm{~min}$. TGA curve of Ezetimibe exhibited a loss of $11.2 \%$ at $300{ }^{\circ} \mathrm{C}$ in $28.42 \mathrm{~min}$. In case of IRBF, only $24 \%$ weight loss was observed at $356{ }^{\circ} \mathrm{C}$ after $33.51 \mathrm{~min}$. TGA spectrum of formulated IRBF displayed that in comparison to the blank drug, the thermal degradation of drug incorporated in film was delayed. A complex might have been developed between drug and the

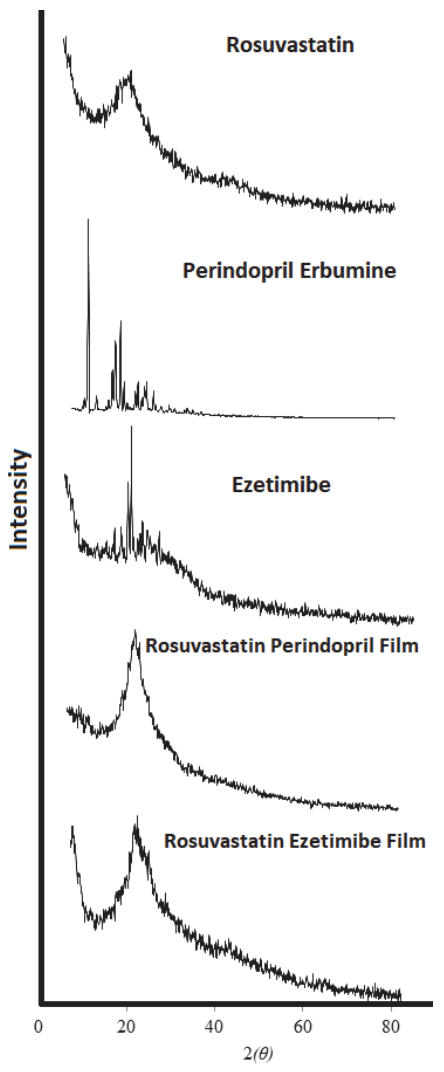

Fig. 3. XRD analysis of individual drugs and IRBFs of drug combinations polymer molecules resulting in better stability. This evaluation illustrated that drug molecules also formed complexes with the super disintegrants due to their instant deteriorating and hydrophilic nature and as a consequence drug became more soluble.

\section{Weight uniformity test}

The weight was found to be directly proportional to the amount of ingredients in each formulation (Table 2). Moreover, the thickness variation of films was also found to be directly proportional to the weight variation (Morales and McConville, 2011). In all formulations, less thickness variation was seen, clearly indicating that the film casting method was suitable.

Tack test

All the formulations were found to be tack free.

\section{Percentage moisture loss}

From the results, it can be found that an increase in PEG 400 increased the percentage moisture content (Table 3), as PEG 400 is a hydrophilic plasticizer (Talja et al., 2007).

\section{Thickness}

The thickness of each film at 3 different positions was measured (Table 4) (Bhupinder and Sarita, 2012). The thickness of a film depends on the quantity of polymeric contents present. An increase in HPMC E5 concentration resulted in an increase in film thickness and vice versa. Standard deviation values of all the formulations were very low showing that variations within the thickness of the films were minor.

\section{Tensile strength}

The tensile strength and folding endurance of IRBFs was enhanced with the increase in plasticizer concentration (Fig. 5). Films with low plasticizer concentrations showed more brittleness and easily broke down. All IRBFs were found to exhibit sufficient elasticity and strength to bear mechanical stress during transportation.

\section{Folding endurance}

The results of the folding endurance test are shown in Table 5. 

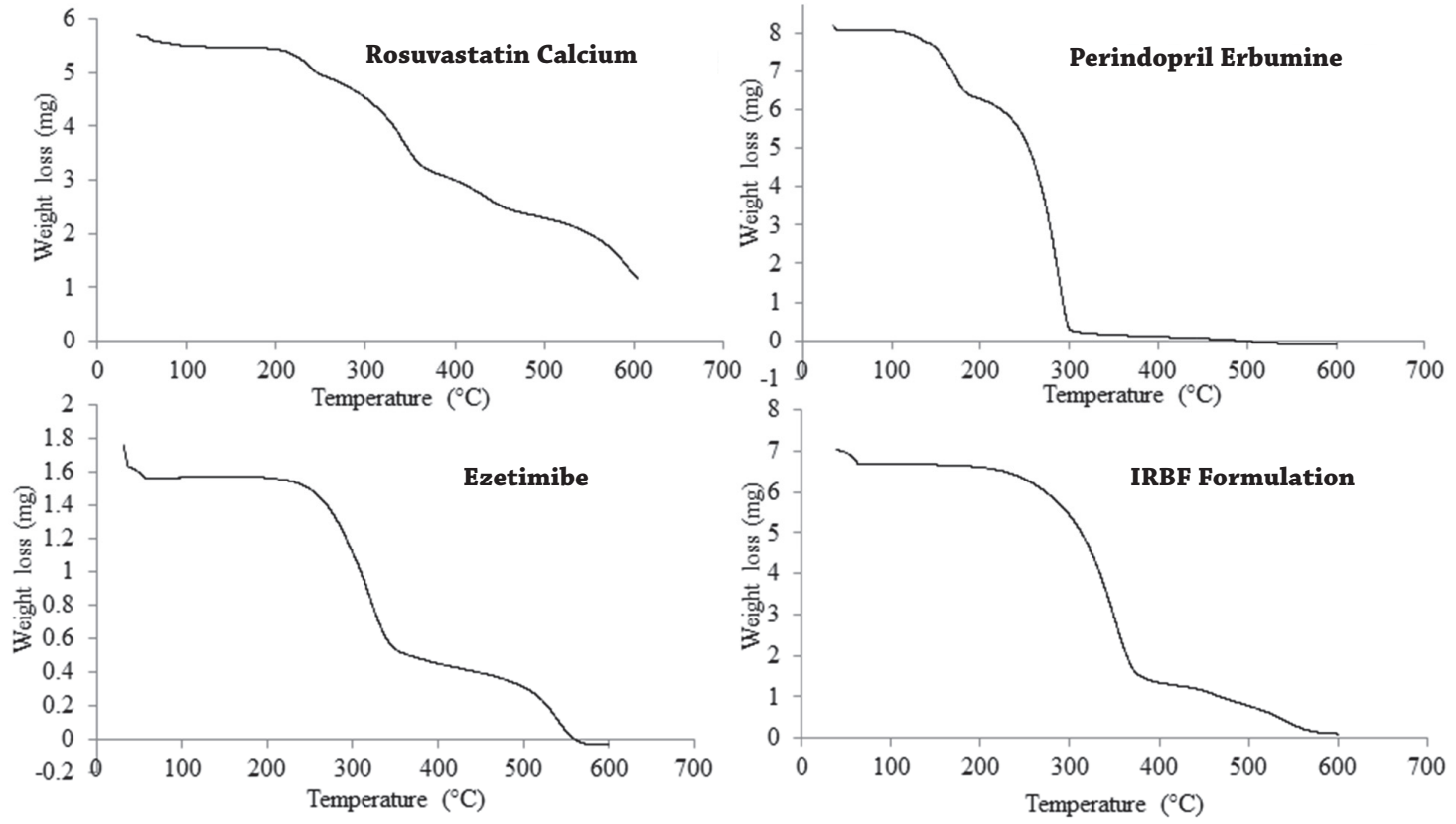

Fig. 4. TGA analysis of individual drugs and an IRBF formulation

Table 2. Weight uniformity test results of different IRBFs

\begin{tabular}{lccccccccccc}
\hline & $\mathrm{R}$ & \multicolumn{2}{c}{$\mathrm{P}$} & & $\mathrm{E}$ & & $\mathrm{PR}$ & $\mathrm{ER}$ \\
\hline Code & $\begin{array}{c}\text { Mean } \\
(\mathrm{mg})\end{array}$ & $\mathrm{SD}$ & $\begin{array}{c}\text { Mean } \\
(\mathrm{mg})\end{array}$ & $\mathrm{SD}$ & $\begin{array}{c}\text { Mean } \\
(\mathrm{mg})\end{array}$ & SD & $\begin{array}{c}\text { Mean } \\
(\mathrm{mg})\end{array}$ & $\begin{array}{c}\text { SD } \\
(\mathrm{mg})\end{array}$ & $\begin{array}{c}\text { Mean } \\
\text { SD }\end{array}$ \\
\hline 5 & 301.867 & 0.125 & 223.433 & 1.907 & 314.4 & 3.785 & 271.367 & 0.974 & 324.967 & 2.949 \\
6 & 249.233 & 0.249 & 180.73 & 1.043 & 296 & 4.060 & 233.133 & 2.674 & 303.9 & 3.471 \\
\hline
\end{tabular}

Table 3. Percentage moisture loss content of IRBF formulations

\begin{tabular}{|c|c|c|c|c|c|c|c|c|c|c|}
\hline \multirow[b]{2}{*}{ Code } & \multicolumn{2}{|c|}{$\mathrm{R}$} & \multicolumn{2}{|c|}{$\mathrm{P}$} & \multicolumn{2}{|c|}{ E } & \multicolumn{2}{|c|}{ PR } & \multicolumn{2}{|c|}{ ER } \\
\hline & $\begin{array}{c}\text { Mean } \\
(\mathrm{mg})\end{array}$ & SD & $\begin{array}{c}\text { Mean } \\
(\mathrm{mg})\end{array}$ & SD & $\begin{array}{c}\text { Mean } \\
(\mathrm{mg})\end{array}$ & SD & $\begin{array}{c}\text { Mean } \\
(\mathrm{mg})\end{array}$ & SD & $\begin{array}{c}\text { Mean } \\
(\mathrm{mg})\end{array}$ & SD \\
\hline 5 & 7.447 & 0.003 & 5.579 & 0.047 & 7.778 & 0.094 & 6.684 & 0.024 & 8.024 & 0.074 \\
\hline 6 & 6.131 & 0.006 & 4.431 & 0.026 & 7.3079 & 0.101 & 5.728 & 0.0667 & 7.497 & 0.087 \\
\hline
\end{tabular}

Table 4. Thickness measurement of various IRBFs

\begin{tabular}{|c|c|c|c|c|c|c|c|c|c|c|}
\hline \multirow[b]{2}{*}{ Code } & \multicolumn{2}{|c|}{$\mathrm{R}$} & \multicolumn{2}{|c|}{$\mathrm{P}$} & \multicolumn{2}{|c|}{ E } & \multicolumn{2}{|c|}{ PR } & \multicolumn{2}{|c|}{ ER } \\
\hline & $\begin{array}{l}\text { Mean } \\
(\mathrm{mm})\end{array}$ & SD & $\begin{array}{l}\text { Mean } \\
(\mathrm{mm})\end{array}$ & SD & $\begin{array}{l}\text { Mean } \\
(\mathrm{mm})\end{array}$ & SD & $\begin{array}{l}\text { Mean } \\
(\mathrm{mm})\end{array}$ & $S D$ & $\begin{array}{l}\text { Mean } \\
(\mathrm{mm})\end{array}$ & $S D$ \\
\hline 5 & 0.110 & 0.008 & 0.090 & 0.002 & 0.113 & 0.017 & 0.137 & 0.009 & 0.145 & 0.005 \\
\hline 6 & 0.117 & 0.012 & 0.093 & 0.001 & 0.121 & 0.020 & 0.133 & 0.009 & 0.138 & 0.002 \\
\hline
\end{tabular}

Table 5. Folding endurance test results

\begin{tabular}{lccccccccccc}
\hline & \multicolumn{2}{c}{$\mathrm{R}$} & \multicolumn{2}{c}{$\mathrm{P}$} & & $\mathrm{E}$ & & PR & ER \\
\hline Code & Mean & SD & Mean & SD & Mean & SD & Mean & SD & Mean & SD \\
\hline 5 & 67.33 & 1.69 & 85.33 & 2.87 & 129 & 0.82 & 102 & 2.16 & 115.33 & 3.29 \\
6 & 60 & 1.63 & 75 & 2.45 & 94.67 & 3.68 & 75.67 & 2.05 & 85 & 3.26 \\
\hline
\end{tabular}




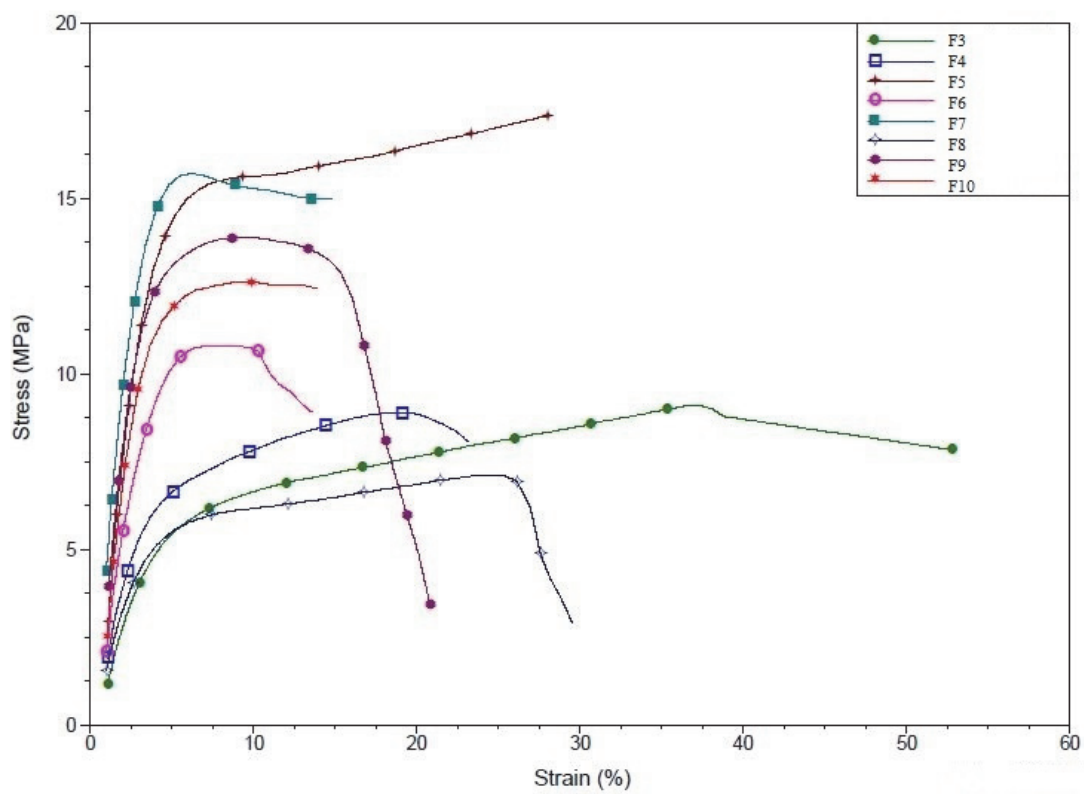

Fig. 5. Tensile strength of various formulations

In vitro Disintegration Time (D.T) and Total Dissolution Time (T.D.T)

IRBFs showed rapid disintegration time ( $\leq 1 \mathrm{~min}$ ) and instant drug release owing to its rapid disintegration (Table 6). T.D.T of IRBFs was found to be $\leq 3 \mathrm{~min}$ (Table 7 ). The $\mathrm{pH}$ of the buccal cavity ranges from 5.5 to 7.4 . The D.T and T.D.T experiments were carried out in distilled water which has a $\mathrm{pH}$ of 7 . Future studies on buccal films should investigate the D.T and T.D.T at both $\mathrm{pH} 5.5$ and 7 so that a clearer picture of disintegration and dissolution characteristics of these films could be obtained.

Table 6. Results of disintegration time of IRBFs

\begin{tabular}{lcccccccccccc}
\hline & \multicolumn{2}{c}{$\mathrm{R}$} & \multicolumn{2}{c}{$\mathrm{P}$} & & $\mathrm{E}$ & & PR & ER \\
\hline Code & $\begin{array}{c}\text { Mean } \\
(\mathrm{sec})\end{array}$ & SD & $\begin{array}{c}\text { Mean } \\
(\mathrm{sec})\end{array}$ & SD & $\begin{array}{c}\text { Mean } \\
(\mathrm{sec})\end{array}$ & SD & $\begin{array}{c}\text { Mean } \\
(\mathrm{sec})\end{array}$ & $\begin{array}{c}\text { SD } \\
(\mathrm{sec})\end{array}$ \\
\hline 5 & 10.393 & 0.090 & 4.393 & 0.037 & 6.033 & 0.033 & 7.207 & 0.017 & 11.090 & 0.016 \\
6 & 11.137 & 0.052 & 9.057 & 0.041 & 6.213 & 0.024 & 14.073 & 0.039 & 13.090 & 0.033 \\
\hline
\end{tabular}

Table 7. Results of total dissolution time of IRBFs

\begin{tabular}{|c|c|c|c|c|c|c|c|c|c|c|}
\hline \multirow[b]{2}{*}{ Code } & \multicolumn{2}{|c|}{$\mathrm{R}$} & \multicolumn{2}{|c|}{$\mathrm{P}$} & \multicolumn{2}{|c|}{$\mathrm{E}$} & \multicolumn{2}{|c|}{$\mathrm{PR}$} & \multicolumn{2}{|c|}{ ER } \\
\hline & $\begin{array}{l}\text { Mean } \\
\text { (min) }\end{array}$ & SD & $\begin{array}{c}\text { Mean } \\
(\mathrm{sec})\end{array}$ & SD & $\begin{array}{c}\text { Mean } \\
(\mathrm{sec})\end{array}$ & SD & $\begin{array}{l}\text { Mean } \\
(\min )\end{array}$ & SD & $\begin{array}{l}\text { Mean } \\
(\mathrm{min})\end{array}$ & SD \\
\hline 5 & 1.477 & 0.021 & 38.333 & 2.494 & 73.333 & 1.247 & 1.303 & 0.012 & 2.457 & 0.031 \\
\hline 6 & 2.057 & 0.039 & 37.333 & 1.247 & 47.667 & 0.943 & 1.327 & 0.009 & 2.413 & 0.026 \\
\hline
\end{tabular}

\section{pH determination}

It can be seen from the results that an increase in the concentrations of plasticizer (PEG 400) and polymer (HPMC E5) slightly increased the pH (Table 8) (Jadhav et al., 2012). This might be due to the fact that drugs are acidic in nature and their acidity was lowered by the addition of these ingredients.

Table 8. $\mathrm{pH}$ measurements of different formulations

\begin{tabular}{|c|c|c|c|c|c|c|c|c|c|c|}
\hline \multirow[b]{2}{*}{ Code } & \multicolumn{2}{|c|}{$\mathrm{R}$} & \multicolumn{2}{|c|}{ P } & \multicolumn{2}{|c|}{ E } & \multicolumn{2}{|c|}{ PR } & \multicolumn{2}{|c|}{ ER } \\
\hline & Mean & SD & Mean & SD & Mean & SD & Mean & SD & Mean & SD \\
\hline 5 & 6.07 & 0.06 & 6.09 & 0.04 & 6.37 & 0.03 & 6.94 & 0.05 & 6.47 & 0.03 \\
\hline 6 & 5.56 & 0.04 & 5.54 & 0.03 & 6.02 & 0.04 & 6.79 & 0.04 & 6.02 & 0.04 \\
\hline
\end{tabular}


Dissolution testing using dissolution apparatus

The results showed that the drug release retarded as the concentration of HPMC E5 increased whereas it was found to be enhanced with the increase in concentration of PEG 400

(Fig. 6) (Mahajan, 2012). Both the polymer and plasticizer affected the drug release.
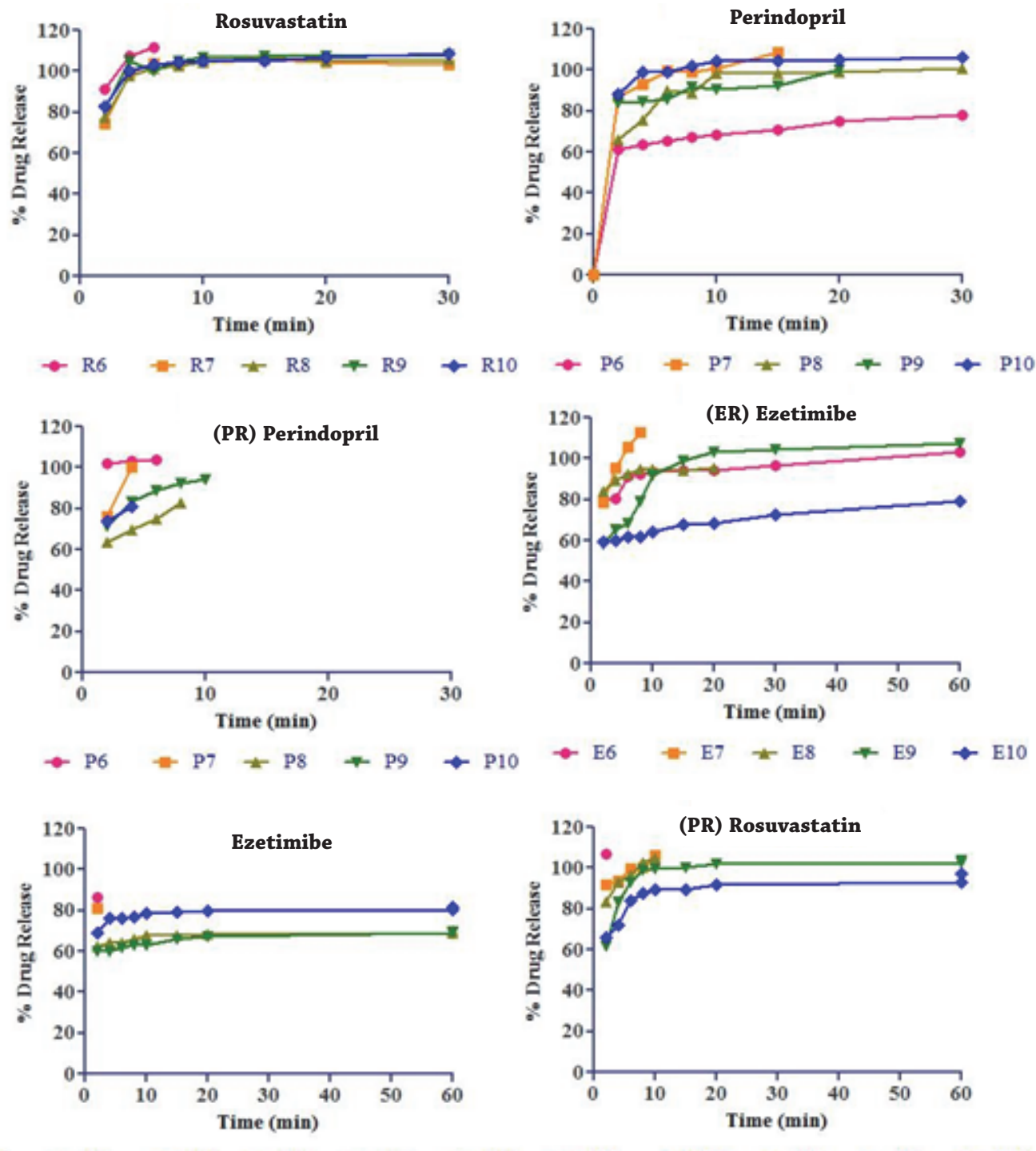

0
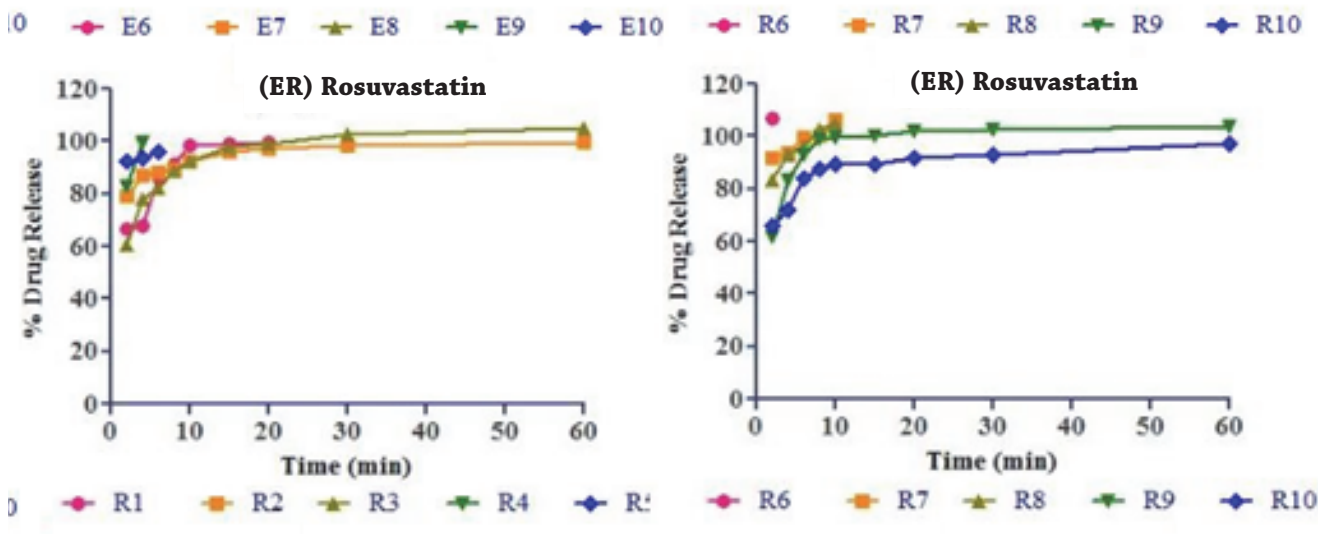

Fig. 6. Dissolution test results using dissolution apparatus 


\section{HPLC analysis}

HPLC analysis has been conducted using mobile phase consisted of Methanol-phosphate buffer-acetonitrile (70:25:5,v/v), adjusted to $\mathrm{pH} 3.5$ using orthophosphoric acid for Rosuvastatin Calcium and Ezetimibe, while for the simultaneous determination of Rosuvastatin Calcium and Perindopril Erbumine, a slight modification has been made in the mobile phase, as methanolic contents were reduced while volume of phosphate
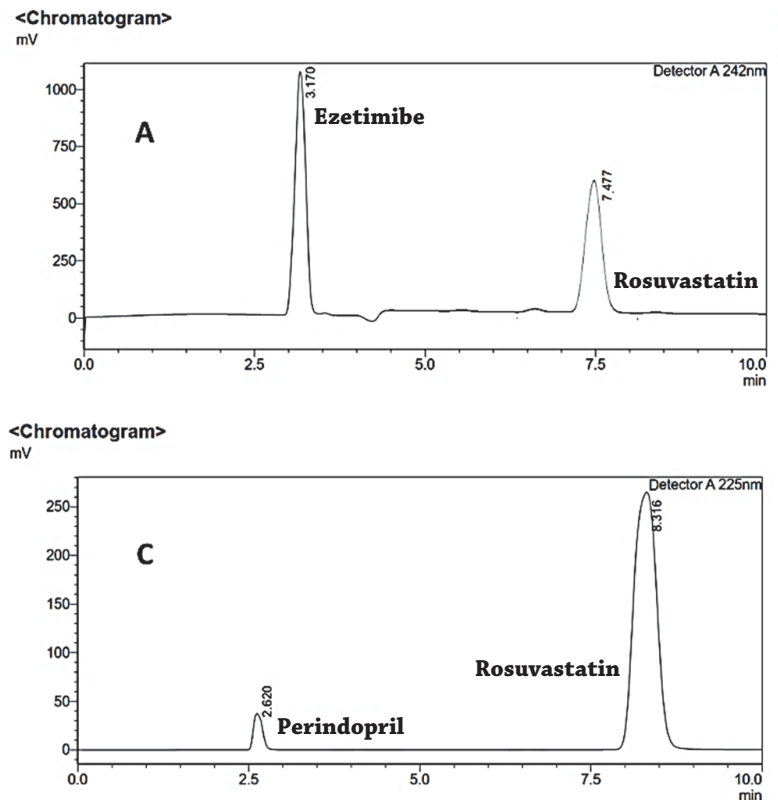

buffer has been increased e.g. Methanol-phosphate buffer-acetonitrile $(60: 35: 5, \mathrm{v} / \mathrm{v})$. other conditions of temperature (ambient), flow rate ( $1 \mathrm{ml} / \mathrm{min}), \mathrm{pH}$ (3.5) and sample run time (10 min) were common for both combinations of the drugs. However, the detection wavelength for Rosuvastatin and Ezetimibe was $242 \mathrm{~nm}$ and for Rosuvastatin and Perindopril was $225 \mathrm{~nm}$ (Fig. 7). Values of $\mathrm{R}^{2}$ for Rosuvastatin, Ezetimibe and Perindopril were $>0.99$ (Fig. 8).
$<$ Chromatogram>

$\mathrm{mV}$

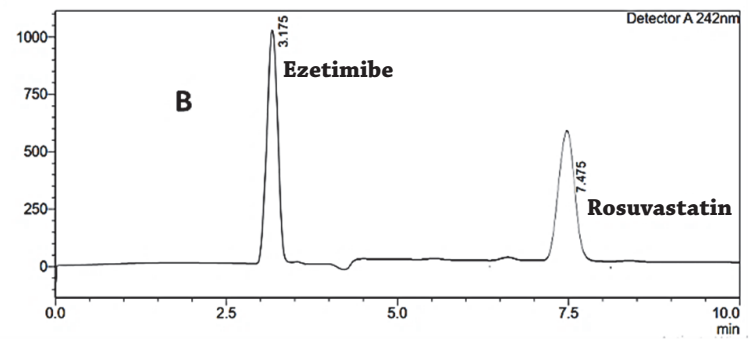

Chromatogram>

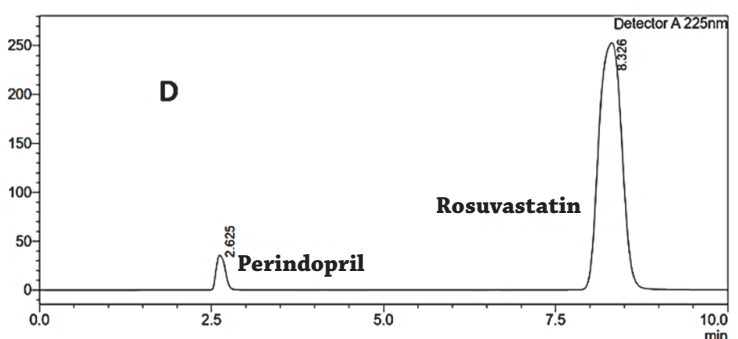

Fig. 7. HPLC chromatograms. (A) standard chromatogram of Rosuvastatin-Ezetimibe, (B) chromatogram obtained after running the sample of films co-loaded with Rosuvastatin-Ezetimibe, (C) standard chromatogram of Rosuvastatin-Perindopril and (D) chromatogram obtained after running the sample of films containing Rosuvastatin-Perindopril
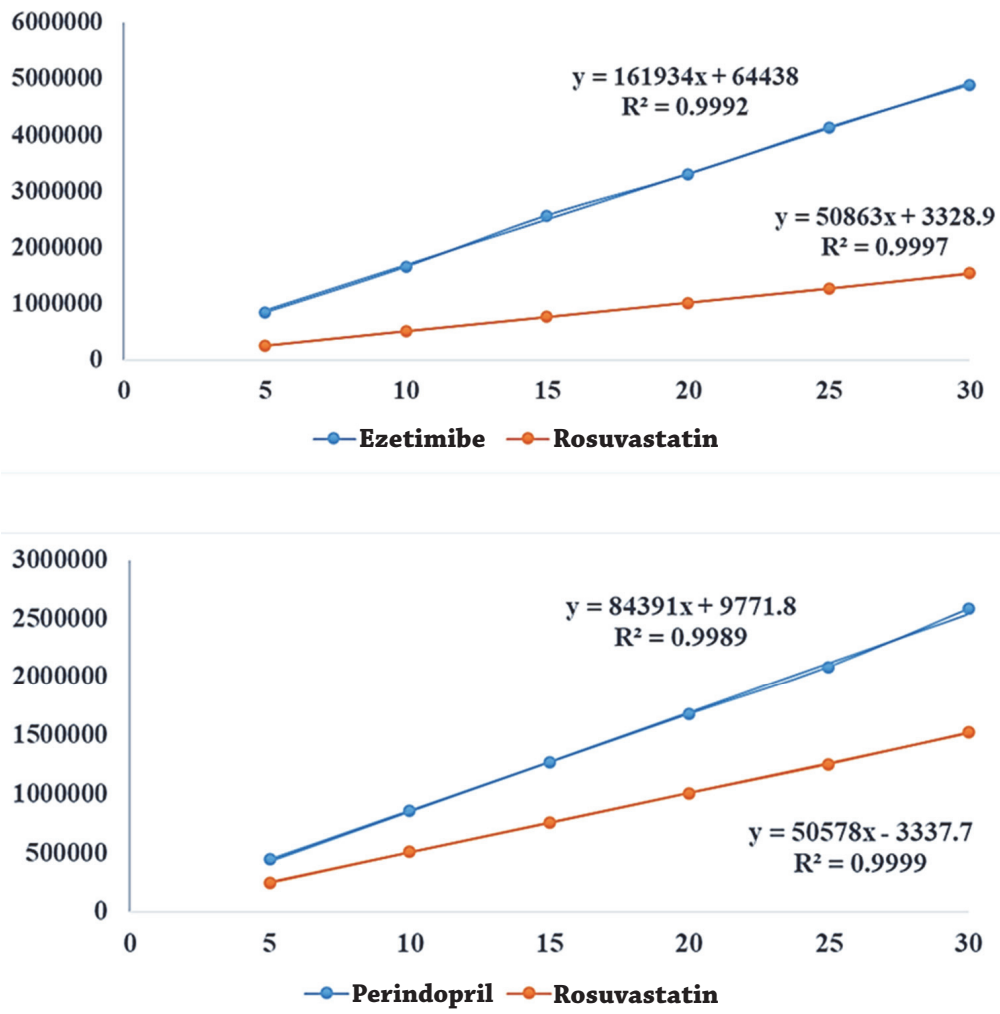

Fig. 8. Linearity graph of Rosuvastatin-Perindopril, and Rosuvastatin-Ezetimibe in the concentration range of 5-30 $\mu \mathrm{g} / \mathrm{ml}$, describing good linearity behavior in the selected concentration ranges 
HPLC analysis has exhibited that the drug contents were 97 to $104 \%$ for all the formulation, confirming the good loading ability of the selected ingredients for film formulation. Furthermore, dissolution samples were analyzed by using HPLC, have advocated the prompt release of the drugs from all the formulations (Formulation encoded as 5 and 6 in Table 1), subjected to HPLC analysis. Rosuvastatin has been released around 100\% from prepared IRBFs within 2 to 6 minutes. On the other hand, Ezetimibe has released in the concentration range of 70 to $100 \%$ in 10 minutes, while the amount Perindopril, release was 70 to $100 \%$ in 2 to 6 minutes (Fig. 9).

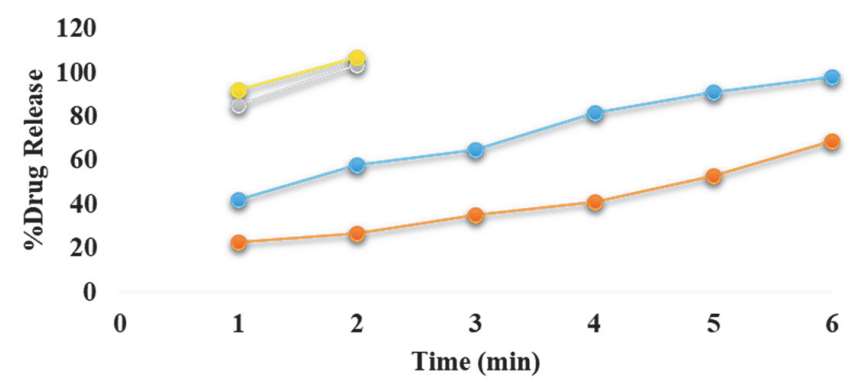

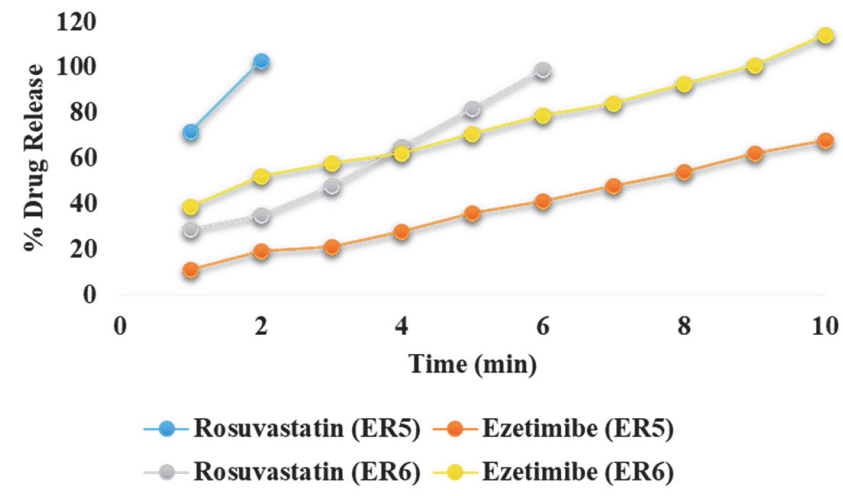

Fig. 9. Drug release of formulations co-loaded with RosuvastatinPerindopril (PR), and Rosuvastatin-Ezetimibe (ER), determined by HPLC, exhibiting prompt release of drugs from the formulated IRBFs

\section{Kinetic modeling of dissolution data}

Dissolution data of Rosuvastatin Calcium, Perindopril and Ezetimibe Formulations were fitted in various kinetic models such as zero order, 1st order, Higuchi and Korsmeyer-Peppas models (Table 9). The values of regression correlation co-efficient $\mathrm{R}^{2}$ were analyzed for all the formulations. Results exhibited that for all IRBFs, $\mathrm{R}^{2}$ had lowest values in zero order kinetic model. So, the drug release per unit time was not constant that was certainly the aspect of controlled release formulations. But $\mathrm{R}^{2}$ in 1 st order kinetic model had highest values for all the IRBFs. Higuchi model narrates the drug release diffusion process containing water-soluble drugs from the matrix systems by Fick's law. Hence, by these high values of $\mathrm{R}^{2}$, it was confirmed that the diffusion mechanism of drug release was nearly followed. In the case of Korsmeyer-Peppas model, R2 values ranged from 0.91 to 0.98 . The $\mathrm{R}^{2}$ values demonstrated diffusion as a mechanism of drug release (Costa and Sousa Lobo, 2001).
Table 9. Kinetic modeling of dissolution data

\begin{tabular}{lccccccc}
\hline \multicolumn{7}{l}{ In-vitro drug release studies } \\
\hline \multicolumn{2}{l}{ Kinetic models } & $\mathrm{R} 5$ & $\mathrm{R} 6$ & $\mathrm{P} 5$ & $\mathrm{P} 6$ & $\mathrm{E} 5$ & $\mathrm{E} 6$ \\
\hline \multirow{2}{*}{ Zero order } & $\mathrm{R}^{2}$ & 0.47 & 0.38 & 0.891 & 0.917 & 0.966 & 0.820 \\
& $\mathrm{k}^{\mathrm{o}}$ & 2.98 & 3.22 & 5.21 & 3.96 & 7.05 & 2.82 \\
\hline \multirow{2}{*}{ 1st order } & $\mathrm{R}^{2}$ & 1.00 & 0.99 & 0.923 & 0.985 & 0.989 & 0.824 \\
& $\mathrm{k}^{1}$ & 0.51 & 1.30 & 0.15 & 0.17 & 0.14 & 0.79 \\
\hline \multirow{2}{*}{$\begin{array}{l}\text { Higuchi } \\
\text { model }\end{array}$} & $\mathrm{R}^{2}$ & 0.97 & 0.92 & 0.922 & 0.996 & 0.932 & 0.816 \\
& $\mathrm{k}_{\mathrm{H}}$ & 21.71 & 23.76 & 20.72 & 19.14 & 15.18 & 20.35 \\
\hline $\begin{array}{l}\text { Korsmeyer- } \\
\text { Peppas } \\
\text { model }\end{array}$ & $\mathrm{R}^{2}$ & 0.93 & 0.92 & 0.900 & 0.977 & 0.919 & 0.824 \\
\hline $\begin{array}{l}\text { Best fit } \\
\text { model }\end{array}$ & $\mathrm{k}_{\mathrm{KP}}$ & 75.43 & 85.90 & 56.90 & 55.88 & 48.32 & 84.33 \\
\hline & 1st & 1 st & 1 st & 1 st & 1 st & 1 st & 1 st \\
order & order & order & order & order & order \\
\hline
\end{tabular}

\section{Dissolution analysis for IRBF formulations}

Mathematical modeling on polynomial equation Mathematical relations constructed using multiple linear regression evaluation of the intended response in which variables are shown in equation 1-7 as:

$Y_{D R}=64.56 B_{0}-4.36 X_{1}+0.11 X_{2}+1.41 X_{1} X_{2}+5.16 X_{1}^{2}+5.67 X_{2}^{2} \quad[(\mathrm{R}) .1]$

$Y_{D R}=56.62 B_{0}-9.06 X_{1}+0.38 X_{2}+0.48 X_{1} X_{2}+10.28 X_{1}^{2}+1.79 X_{2}^{2} \quad$ [(P). 2]

$Y_{D R}=65.93 B_{0}-11.96 X_{1}+1.58 X_{2}+1.80 X_{1} X_{2}+7.37 X_{1}^{2}+2.86 X_{2}^{2} \quad$ [(E).3]

$Y_{D R}=60.56 B_{0}-16.91 X_{1}+0.76 X_{2}+0.97 X_{1} X_{2}+13.45 X_{1}^{2}+2.96 X_{2}^{2}$ [(R) PR. 4]

$Y_{D R}=65.66 B_{0}-14.53 X_{1}+0.34 X_{2}-2.55 X_{1} X_{2}+7.20 X_{1}^{2}+1.72 X_{2}^{2}$ [(P) PR. 5]

$Y_{D R}=79.40 B_{0}+7.49 X_{1}-1.24 X_{2}-6.12 X_{1} X_{2}+0.37 X_{1}^{2}-6.70 X X_{2}^{2}$ [(R) ER. 6]

$Y_{D R}=58.91 B_{0}-5.89 X_{1}+3.12 X_{2}-17.72 X_{1} X_{2}+3.47 X_{1}^{2}+5.02 X X_{2}^{2}[(E) E R .7]$

From the equations, it was noticed that HPMC E5 exerted a negative effect while PEG 400 had influenced positively. Both interacting factors $\mathrm{X}_{1} \mathrm{X}_{2}$ have positive values, which indicated that mean simultaneous variation in both $\mathrm{X}_{1}$ and $\mathrm{X}_{2}$ enhanced the dissolution of the films.

Reasons of delay in the release of the drug with increase in the concentration of the polymer is because it increases the thickness of the film, resulting in more dissolution time. Moreover, HPMC has the ability to form a gel layer around the particles of the drug, more polymeric content means greater thickness of the gel layer, causing drug to travel more distance to reach the liquid medium. In case of the swelling matrix from the dissolution media, when water passed through the matrix, it initiated the drug release. To form a gel like structure, polymer got hydrated with water which dissolved the drug and relaxed the polymeric chains. As a consequence, the drug dispersed out of the matrix. Drug solubility is an essential parameter that effects the release of the drug (Zaman et al., 2013). The presence of PEG 400 as plasticizer in the buccal film provides elasticity and plasticity. In addition, PEG 400 was efficacious in the augmentation of drug dissolution due to its hygroscopic nature. PEG also reduced the viscosity of the polymeric gel resulting in enhanced release of the drug from the formulations (Abd Elbary et al., 2012).

\section{Conclusions}

The current study was adapted to fabricate the instant release buccal films (IRBFs) of Rosuvastatin Calcium, Perindopril 
Erbumine and Ezetimibe in the treatment of hypertension and hypercholesterolemia. The IRBFs of Rosuvastatin Calcium, Perindopril Erbumine and Ezetimibe were formulated effectively with satisfactory dissolution and disintegration results. The formulations exhibited anticipated outcomes individually as well as in combination. The results displayed that all drugs, polymers and plasticizers used were suitable. They exhibit potential by increasing the patient compliance thereby reducing chances of dose failure as well as quick onset of action, and secondly, by mitigating the cost of the treatment as an outcome of intermixing two drugs in single mixture film. The safety and compatibility of these formulations with buccal mucosa are still required to be thoroughly studied. Our findings could potentially be extrapolated and translated to clinical practice if the oral cavity/buccal mucosa is rinsed with distilled water prior to the application of buccal films hence simulating the clinical situation almost similar to the experimental model. Furthermore, in vivo pharmacokinetic study to investigate inter-individual variability in bioavailability is recommended.

\section{Conflict of interests}

The authors declare no conflict of interests.

\section{Acknowledgements}

The authors would like to acknowledge The University of Lahore for providing facilities and resources to conduct the research.

\section{References}

Abd Elbary A, Ali AA, Aboud HM (2012). Enhanced dissolution of meloxicam from orodispersible tablets prepared by different methods. Bull Fac Pharm Cairo Univ 50: 89-97. DOI: 10.1016/j. bfopcu.2012.07.001.

Bajdik J, Marciello M, Caramella C, Domján A, Süvegh K, Marek T, Pintye-Hódi K (2009). Evaluation of surface and microstructure of differently plasticized chitosan films. J Pharm Biomed Anal 49(3): 655-659. DOI: 10.1016/j.jpba.2008.12.020.

Bhupinder B, Sarita J (2012). Formulation and evaluation of fast dissolving sublingual films of Rizatriptan Benzoate. Int J Drug Dev Res 4(1): 133-143.

Chatap VK, Karale AM, Wagh P, Deshmukh PK, Savita SD, Bari SB (2013). Fabrication of Specially Designed Novel Mould for Casting of Perindopril Erbumine Mouth Dissolving Film. Adv Pharmacol Pharm 1(2): 58-67. DOI: 10.13189/app.2013.010203.

Chaudhary H, Gauri S, Rathee P, Kumar V (2013). Development and optimization of fast dissolving oro-dispersible films of Granisetron $\mathrm{HCl}$ using Box-Behnken statistical design. Bull Fac Pharm Cairo Univ 51: 193-201. DOI: 10.1016/j.bfopcu.2013.05.002.

Chou DK, Krishnamurthy R, Randolph TW, Carpenter JF, Manning MC (2005). Effects of Tween $20^{\circledR}$ and Tween $80^{\circledR}$ on the stability of Albutropin during agitation. J Pharm Sci 94(6): 1368-1381. DOI: 10.1002/jps.20365.

Costa P, Sousa Lobo JM (2001). Modeling and comparison of dissolution profiles. Eur J Pharm Sci 13(2): 123-133. DOI: 10.1016/S0928-0987(01)00095-1.

Durrington P (2003). Dyslipidaemia. Lancet 362(9385): 717-731. DOI: 10.1016/S0140-6736(03)14234-1

El-Setouhy DA, El-Malak NSA (2010). Formulation of a novel tianeptine sodium orodispersible film. AAPS PharmSciTech 11(3): 1018-1025. DOI: 10.1208/s12249-010-9464-2.
Hanif M, Zaman M, Chaurasiya V (2015). Polymers used in buccal film: a review. Des Monomers Polym 18(2): 105-111. DOI: 10.1080/15685551.2014.971389.

Irfan M, Rabel S, Bukhtar Q, Qadir MI, Jabeen F, Khan A (2016). Orally disintegrating films: a modern expansion in drug delivery system. Saudi Pharm J 24(5): 537-546. DOI: 10.1016/j. jsps.2015.02.024.

Jadhav SD, Kalambe RN, Jadhav CM, Tekade BW, Patil VR (2012). Formulation and evaluation of fast dissolving oral film of levocetirizine dihydrochloride. Int J Phar Pharm Sci 4(Suppl. 1): 337-341.

Kianfar F, Chowdhry BZ, Antonijevic MD, Boateng JS (2012). Novel films for drug delivery via the buccal mucosa using model soluble and insoluble drugs. Drug Dev Ind Pharm 38(10): 1207-1220. DOI: 10.3109/03639045.2011.644294.

Kumar SK, Nagabhushanam MV, Rao KRSS, Bhikshapathi DVRN (2013). Preparation and in vivo evaluation of oral dissolving films containing sumatriptan succinate. Der Pharm Lett 5(3): 27-38.

Kumria R, Nair AB, Goomber G, Gupta S (2016). Buccal films of prednisolone with enhanced bioavailability. Drug Deliv 23(2): 471-478. DOI: 10.3109/10717544.2014.920058.

Mahajan A (2012). Formulation and evaluation of fast dissolving buccal films of sertraline. Int J Drug Dev Res 4(1): 220-226.

Morales JO, McConville JT (2011). Manufacture and characterization of mucoadhesive buccal films. Eur J Pharm Biopharm 77(2): 187-199. DOI: 10.1016/j.ejpb.2010.11.023.

Nair AB, Kumria R, Harsha S, Attimarad M, Al-Dhubiab BE, Alhaider IA (2013). In vitro techniques to evaluate buccal films. J Control Release 166(1): 10-21. DOI: 10.1016/j. jconrel.2012.11.019.

Patel DA, Patel MR, Patel KR, Patel NM (2012). Buccal mucosa as a route for systemic drug delivery: A review. Int J Drug Dev Res 4(2): 99-116.

Prabhu P, Malli R, Koland M, Vijaynarayana K, D’Souza U, Harish NM, et al. (2011). Formulation and evaluation of fast dissolving films of levocitirizine di hydrochloride. Int J Pharm Investig 1(2): 99-104. DOI: 10.4103/2230-973X.82417.

Preis M, Woertz C, Kleinebudde P, Breitkreutz J (2013). Oromucosal film preparations: classification and characterization methods. Expert Opin Drug Deliv 10(9): 1303-1317. DOI: $10.1517 / 17425247.2013 .804058$.

Quirk J, Thornton M, Kirkpatrick P (2003). Rosuvastatin calcium. Nat Rev Drug Discov 2(10): 769-770. DOI: 10.1038/nrd1205.

Shojaei AM, Chang RK, Guo X, Burnside BA, Couch RA (2001). Systemic drug delivery via the buccal mucosal route. Pharm Technol 25: 70-81.

Tabrizi JS, Sadeghi-Bazargani H, Farahbakhsh M, Nikniaz L, Nikniaz Z (2016). Prevalence and associated factors of prehypertension and hypertension in Iranian population: the lifestyle promotion project (LPP), PloS One 11(10): e0165264. DOI: 10.1371/journal.pone.0165264.

Talja RA, Helén H, Roos YH, Jouppila K (2007). Effect of various polyols and polyol contents on physical and mechanical properties of potato starch-based films. Carbohydr Polym 67(3): 288-295. DOI: 10.1016/j.carbpol.2006.05.019.

Tummala S, Kumar MS, Prakash A (2015). Formulation and characterization of 5-Fluorouracil enteric coated nanoparticles for sustained and localized release in treating colorectal cancer. Saudi Pharm J 23(3): 308-314. DOI: 10.1016/j.jsps.2014.11.010.

Zaman M, Adnan S, Saeed MA, Farooq MA, Masood Z, Chishti SA, et al. (2013). Formulation and in-vitro evaluation of sustained release matrix tablets of cellulose based hydrophilic and hydrophobic polymers loaded with loxoprofen sodium. Indo American J Pharma Res 3(9): 7389-7398. 